\title{
Scientific Realism, Metaphysical Antirealism and the No Miracle Arguments
}

\author{
Mario Alai ${ }^{1,2}$ (D) \\ Published online: 9 August 2020 \\ (c) The Author(s) 2020
}

\begin{abstract}
Many formulations of scientific realism (SR) include some commitment to metaphysical realism (MR). On the other hand, authors like Schlick, Carnap and Putnam held forms of scientific realism coupled with metaphysical antirealism (and this has analogies in Kant). So we might ask: do scientific realists really need MR? or is MR already implied by SR, so that SR is actually incompatible with metaphysical antirealism? And if MR must really be added to SR, why is that so? And which additional arguments scientific realists need to support it? After reviewing and classifying a number of different kinds of realisms, metaphysical and not, I answer that SR and MR are logically independent of each other, so that there is no logical inconsistency in holding SR while rejecting MR. However, I argue that the "no miracle" argument (NMA) not only is the "ultimate" argument for SR, but by the same token it also supports MR. Therefore one cannot effectively defend SR without also subscribing to MR, but this can be done at no additional argumentative cost. I show this by discussing not only the standard version of the NMA, but also three more versions which are not usually considered as such in the literature.
\end{abstract}

Keywords Scientific realism · Metaphysical realism - Empirical realism · Internal realism · No miracle argument · Verificationism · Constructivism · Phenomenism · Putnam ·

Schlick · Carnap

\section{Scientific and Metaphysical Realism}

Many formulations of scientific realism (SR) include some commitment to metaphysical realism (MR) (for instance, with clauses like "... and theoretical entities exist mindindependently", or "... and theories are true in the correspondence sense"). ${ }^{1}$ Is this really needed? i.e. (a) isn't MR already implied by SR? And (b) if it is not, is MR necessary

\footnotetext{
1 For Psillos scientific realism has three components, one of which is the metaphysical thesis that "the world has a definite and mind-independent structure" (2005, p. 688).
}

Mario Alai

mario.alai@uniurb.it

1 Università di Urbino Carlo Bo (DiSPeA), Urbino, Italy

2 Académie Internationale de Philosophie des Sciences, Brussels, Belgium 
to defend SR? In other words, could one consistently hold SR without MR, or even with metaphysical antirealism (MAR)? And if so, would SR be defensible without MR, or even with MAR? If, instead, scientific realists need or just wish to endorse MR as well, do they have good arguments for it?

In 1977 Hilary Putnam argued that one can (and should) hold an "internal" form of SR coupled with MAR. But before him even Schlick and Carnap had taken similar views. Apparently this makes sense, especially if one takes MR to be a stronger form of realism, such that it implies SR without being implied by it.

In my view not only SR\&MAR is a logically consistent conjunction, but there is a useful point of view from which SR neither implies nor is implied by MR, so that SAR\&MR (the conjunction of scientific antirealism and MR) is also consistent, as well as SR\&MR and SAR\&MAR. However, I will argue that SR\&MAR is not defensible. This is because, as Putnam himself pointed out, the best and probably the only decisive case for SR is the "no miracle" argument (NMA), and I maintain that by the same token and with equal force the NMA also supports MR. Thus, scientific realists could avoid all metaphysical commitments only by rejecting the NMA, but in so doing they would also cut the branch on which they sit. This is why MR is not only not superfluous for them, but also comes at no additional argumentative costs.

I will show this by discussing not only the typical NMA concluding to the (approximate) truth of theories from the success of science, but three more arguments which can also be called "NMA", because they argue that MR is the only non-miraculous explanation of certain facts about the physical world and our knowledge of it. Therefore scientific realists using the classical NMA are committed at least to the general inferential form of these arguments. In so doing I shall also compare the current debate on MR with certain past debates on the same subject, and point out that the relationship between SR and MR has analogies in those debates.

The first task, therefore, is to understand precisely what SR and MR are, and what their logical relationship is. Putnam did not clearly define MR, but characterized it in vague and not completely consistent ways. Initially, in addition to contrasting it with "internal" realism, he described MR as the "model" according to which "the world consists of some fixed totality of mind-independent objects", so that "there is exactly one true and complete description of "the way the world is", and "truth involves some sort of correspondence relation between word or thought-signs and external things and sets of things" (1981, 49, 1977, 123-125). A few pages later, however, he granted that there can be also a "sophisticated" version of MR: according to the latter the world can be sliced up in different ways, like cookies from the dough, or mapped by different projections like the Earth on the planisphere-so that different apparently incompatible theories can be equally correct (1977, 129-130, 1981, 73-74, 1987, 31).

Putnam rejected "hard core" MR, the single true theory version, with his "model-theoretic" argument, according to which all the possible constraints on reference would allow many incompatible theories to come out true of the world, which then would remain an unknowable noumenon (1977, 125-127). His critics replied that there are more constraints on reference which he did not consider, but we cannot deal with this now. Putnam also rejected "sophisticated" MR by arguing that there are so many ways to "slice up" the world that no property of the world will be preserved by all the correct theories: therefore all properties are merely theory-relative, and again the world becomes "a mere "thing in 
itself"." ${ }^{2}$ As a way out, he then proposed a verificationist reinterpretation of all scientific (and everyday) discourse à la Dummett (1977, 127-129). I criticized Putnam's second argument in (1994, §§ 3.4-3.7), but again I cannot discuss it here, except by noticing that Putnam himself later recanted it, going back to a form of sophisticated MR. ${ }^{3}$

Many years later Putnam acknowledged that his characterizations in (1977) and (1981) had been imprecise and even inconsistent, and that "there is a natural understanding of the phrase 'metaphysical realism' in which it refers to a broad family of positions" (2012, 54, 62 ). Since the term is still used in such a vague way, in order to assess the co-tenability of SR and MAR (metaphysical antirealism) we need to bring out at least a core of characters shared by most of those positions: something more structured than mere Wittgensteinian family resemblances, albeit less rigid than a Carnapian "explicative definition". The latest Putnam eventually identified MR with the conjunction of "(1) the rejection of verificationism and (2) the denial of conceptual relativity"4 $(2012,101)$, and I believe he was substantially right; but to see why, let's take a short look at the history of the term 'MR'.

To begin with, of course Putnam was aware that Carnap had considered the classical realism about the external world a metaphysical claim, as opposed to merely empirical existence claims (1928, §§ 9-10), and the same distinction had been made by Schlick (1932b, 1936). So what Putnam meant by 'MR' could not be too different from what both meant. For them MR could not in principle be empirically supported, hence (given their verificationist theory of meaning) it was meaningless. In turn, it couldn't have escaped Schlick or Carnap that Kant too had criticized metaphysics for lacking all empirical support, but in so doing he had endorsed "empirical realism" within the framework of "transcendental idealism" (i.e., MAR) (1781-1787, A 369-370, ff.). Finally, these stands resembled Berkeley's way to account for everyday physical objects by maintaining that they exist, and indeed can be directly perceived, while holding that they are mind-dependent.

These distinctions are not exactly coincident, but let's see what they have in common. Realism is a claim that some target $\mathrm{X}$ (typically a kind of entities) really exists and/or is as it appears to be, and that it is really known and really referred to. Thus a realism debate appears when doubts arise as to how things and our cognitive relations to them seem to be (Alai 1994, 24-26).

Although the extension of the term 'MR' is not precisely defined in current usage, realism tends to be called "metaphysical" when it reacts to very basic and in-principle doubts sweeping across the entire reality, or at least one of its main dimensions (like the physical world, the sphere of the mental, the realm of abstract entities or that of social objects). This tendency probably exists because metaphysics nowadays is commonly understood with two main connotations: the classical idea that it concerns the most general and fundamental aspects of reality (being as being) and the more recent idea that is undecidable by ordinary empirical or rational evidence, for it aims to transcend the subjective limits of knowledge, in order to provide the deepest and most objective account of things.

MAR is rarely radical, however, for it would be paradoxical to deny that there exists a world at all, or that a physical world (or a mental world, or universals, etc.) exist at all; moreover, it would also be paradoxical to deny that we can talk about them or know them

\footnotetext{
2 Putnam (1977, 133, 1987, 32) and Alai (1994, 114-118).

3 Alai (1994, §§ 3.4-3.7) and Putnam (1994, 2012, 53-64, 101-102).

${ }^{4}$ He certainly meant, more precisely "the denial of conceptual relativism (i.e., of constructivism), since conceptual relativity is an undeniable fact. See Sect. 5 below.
} 
at all. ${ }^{5}$ More often, therefore, antirealists simply downgrade either the world or some of its main dimensions (in short: the WorlD) to a lower degree of reality (existence, and/or reference and/or knowledge). Thus they embrace a non-metaphysical realism, which Kant called "empirical" (as opposed to "transcendental", i.e., metaphysical), and Putnam called "internal". 6

Soon we shall see some examples, but first a few details and clarifications. A higher degree of reality implies a lower one; therefore we should distinguish non-metaphysical realism, which is compatible with MR, from MAR, which is the negation of MR. Besides, various lower and lower degrees of reality may be envisaged with respect to any target X, so we may encounter different weaker and weaker levels of realism on X.

MR holds that the WorlD enjoys the highest degree of reality, in spite of the most basic and general objections or doubts about it. However, further more specific doubts may arise about some particular area $x$ of the WorlD, and then we have a special realism debate about $x$. In these circumstances metaphysical realists may or may not believe that the specific objections about $x$ can be answered, and in the latter case they deny that $x$ enjoys the same degree of reality as the rest of the WorlD. Obviously MR does not claim that everything seemingly real is metaphysically so, but only that the WorlD typically enjoys the highest degree of reality, or that at least some putative components of the WorlD do. MAR instead holds that nothing is metaphysically real. (More generally, any level of realism about X holds that at least some items putatively belonging to $\mathrm{X}$ are real at that level).

For instance, the debates on SR are special debates about the unobservable entities postulated by theories (ue), which arise from very specific objections, like the lack of (direct) empirical evidence, the empirical underdetermination of theories or the pessimistic metainduction. A metaphysical realist may or may not believe that these specific problems can be solved; if the latter, s/he holds SAR (scientific antirealism)-i.e., she does not believe the ue enjoy the highest degree of reality; however s/he may grant they enjoy some lower degree of reality. Another metaphysical realist, instead, may believe that only the "scientific image" is real in the strongest sense, i.e. that only the ue are metaphysically real, while the "manifest image", viz. the ordinary observable objects and properties, are not.

Vice versa, metaphysical antirealists advance very general and basic objections, arguing that nothing is metaphysically real, obviously including ue. However, they may or may not believe that the special objections concerning the ue can be answered. If the former, they hold SR; i.e., they believe that ue enjoy at least the same non-metaphysical degree of reality enjoyed by other entities (typically, in these debates, by ordinary observable objects and properties (oop)).

As such, the SR-SAR debate is unconcerned with the more general worries and arguments underlying the MR-MAR debates, and its special problems are left untouched no matter what solution is given to those more general debates.

MR is then the claim that the WorlD is real to the highest degree since (a) it exists and has properties (b) it can be referred to and (c) it can be known, each in the strongest possible senses, as I shall detail below. In contrast, SR is the claim that ue enjoy, at the least, the highest degree of reality available to the rest of the (physical) world, whatever that degree is. In this sense, MR\&SR, MR\&SAR, MAR\&SR, and MAR\&SAR are all logically consistent conjunctions. In particular, in Sects. 3 and 5 I shall explain how various forms of

\footnotetext{
5 Such radical denials are very rare: nihilists deny that anything exists, skeptics deny that we can know anything and eliminative materialists deny that mental entities exist.

${ }^{6}$ Kant (1781-1787, A370) and Putnam (1977, 123 ff).
} 
SR are logically compatible with various forms of MAR, although in Sects. 4 and 6 I shall argue that MR, while not implied by SR, is required to support it. In a way, the relation between SR and MR is then similar to that between Carnap's (1950) internal and external questions: once a general framework is chosen (i.e., the highest degree of reality enjoyed by the WorlD is specified) it must be decided whether ue are part of that framework or not.

The same compatibility between non-metaphysical forms of realism (e.g., SR) and MAR characterizing the contemporary debate can be appreciated in older debates. Berkeley's basic worry was that we cannot make sense of external objects starting from our internal ideas, so he denied that oop (ordinary objects and properties) are mind-independent: this denial was his MAR. However, he then granted that oop exist mind-dependently, and this was his non-metaphysical realism.

Kant's general problem was that the WorlD cannot be taken to correspond to our a priori forms of intuition and thought, so he denied that the WorlD in itself is as we perceive and conceptualize it, holding that things are mere "phenomena": this was his MAR. However he maintained that phenomena can be "objective"-i.e., their appearance is necessary and universally valid-and this was his non-metaphysical realism. Moreover, in this way he was able to defend a special realism about oop, arguing against Berkeley that, although phenomenical, they are actually "external".

The neopositivists' basic and wide-sweeping objection was that since sentences cannot have truth conditions, but only verification conditions, we cannot talk about any verification-transcendent reality (any reality "in itself”), but only about our experiences (MAR). However, they thought all the sentences of science and commonsense keep their truth value when understood verificationistically (non-metaphysical realism). In particular, they held a special realism on $u e$, maintaining that sentences about them, once verificationistically interpreted, could be confirmed (hence accepted as true) in spite of possible antirealist doubts.

Putnam's basic objections included both the model-theoretic argument for the indeterminacy of reference and the idea, very similar to Kant's, that our conceptual schemes veil the metaphysical nature of things. Still he thought that once reference and truth are understood verificationistically we can assert pretty much the same sentences as usual, and in particular sentences about ue can be upheld against the specific worries of SAR.

\section{Different Kinds of Realist Claims}

\subsection{Ontologic Claims}

Let's now review in more details various forms of realist claims, both metaphysical and not. There are three main kinds: ontologic, semantic and epistemic. Possible ontologic realist claims about a target $\mathrm{X}$ are the following:

OR1: $\mathrm{X}$ exists (rather than not existing).

OR2: $\mathrm{X}$ is irreducible to something else (i.e. it is a fundamental constituent of reality); for instance physical objects are not just ideas (the physical is not reducible to the mental), or mental states are not just brain states (the mental is not reducible to the physical). 
OR3: X exists objectively, i.e. independently of being perceived, conceptualized, thought or known. ${ }^{7}$ This is often phrased as being mind-independent, and typically what is objective is also mind-independent. However, this is not always the case: e.g., a state of mind is (obviously) mind-dependent, but it is objective since it exists independently of being known or even noticed by anybody, including the subject or her psychoanalyst. Conversely, for intuitionists mathematical entities are not mental entities, but their existence depends on their being constructed by thought.

Further ontologic realist claims are:

OR4: X has properties, or relations, or a certain nature, structure or constitution (in short: properties).

OR5: X's properties are irreducible to something else. For instance, emergentism holds that biological properties are irreducible to chemical or physical properties, that mental properties are irreducible to physical properties, etc.

OR6: X's properties are objective (in the sense of OR3). For instance, Einstein et al. (1935) held that certain properties of particles are independent of measurement.

Therefore, OR1 is entailed by each of OR2-OR6, but not vice versa; OR4 is entailed by OR5 and OR6, but not vice versa. The negation of each of OR1-OR6 is a possible form of ontologic antirealism.

If $\mathrm{X}$ is the WorlD, OR1 and OR4 are not usually seen as realist claims, because everybody agrees that the WorlD exists and has properties, and a doctrine counts as realist only when it is not plainly accepted by everybody. Instead, existence and the possession of properties may be questioned for more specific targets. However idealists deny that the WorlD exists objectively, and Kant denies that its properties are objective. On the other hand, Berkeley rejects OR2 on the physical world, claiming that it is mind-dependent, while reductionist materialists reject OR2 on the mental world, claiming that it is reducible to the physical world. All of these are forms of ontologic MAR. In contrast, ontologic MR consists of OR2-OR6 concerning the WorlD.

\subsection{Semantic Claims}

Some debates between realism and antirealism concern semantics, i.e., whether it is even possible for us (or for language) to refer to a certain target X. Since these debates stem from general worries concerning the functioning of language, they apply to everything we can talk about, i.e., to the entire WorlD. For this reason I consider semantic realism as a form of MR, and semantic antirealism as a form of MAR, and Putnam considered semantic realism as the first component of $\operatorname{MR}(2012,101)$.

There is a trivial, or "internal", sense of 'referring' in which there is no question that we refer to things. ${ }^{8}$ For instance, Putnam says that if 'refers' is not a primitive notion of semantics, but is introduced à la Tarski, then it is a tautology that 'cow' refers to cows, or 'electron' refers to electrons $(1977,128)$. So, granting reference in this trivial sense is a form of "internal" (non-metaphysical) semantic realism. Instead, semantic MR holds that

\footnotetext{
7 Notice, this is not how Kant uses the term 'objective', for he understands it as 'intersubjectively valid'.

${ }^{8}$ More precisely, in which everybody agrees that we refer to any existent thing for which we have a word.
} 
we really refer to the apparent referents, as opposed to something else or to nothing at all. In these examples what MR claims and MAR denies is that the words 'cow' and 'electron' in their second occurrence (in which they are used rather than mentioned) actually refer to (respectively) the snow and electrons (Putnam 1978a, 27-33, 1977, 128). Semantic MAR is backed by (or basically consists of) verificationism, according to which the meaning of sentences consists in their conditions of verification, where 'verification' may mean either an infallible proof (strict verification), or just a fallible confirmation, or simply appropriate assertibility. For verificationism any statement of the form ' $s$ is $\mathrm{P}$ ' does not mean that $s$ is $\mathrm{P}$, but that certain conditions obtain in which ' $s$ is $\mathrm{P}$ ' is verified, or confirmed, or assertible. Depending on how these conditions are understood, we get three different varieties of verificationism:

phenomenist verificationism: What verifies or confirms sentences are sensations, therefore sentences refer not to their apparent referents, but just to sensations;

reductionist verificationism: What verifies or confirms sentences (including those about ue) are observable states of things, therefore sentences don't refers to their apparent (unobservable) referents but to observable things and states;

assertibiblity verificationism: There are no particular things that verify or confirm sentences, but just conditions in which sentences are correctly assertible by the conventions ruling the linguistic practice of the relevant scientific community or social group; so, a sentence $\mathrm{S}$ does not refer to its apparent referents, but simply says that conditions are such that $\mathrm{S}$ is assertible (Putnam 1977, 127-129).

Phenomenist and reductionist verificationism have been held by various neopositivists. ${ }^{9}$ As explained by Putnam, for them there was still "a basis of hard facts" (i.e., of objective things) about which language speaks (respectively, sensations, and observable states of things). Instead assertibility verificationism, held by Putnam himself and based on Dummett's theory of meaning, is "verificationist all the way down", without any rock bottom of objective verification conditions (Putnam 1977, 127-129). This is why from Putnam's (1977) point of view language only speaks of irreducibly subjective assertibility conditions, i.e., of the judgments of a certain linguistic community (a disciplinary community or other social group). ${ }^{10}$ In practice, a sentence ' $S$ ' says that everything is as if ' $S$ ' were true as far as the linguistic practice of the relevant community is concerned. Instead, semantic MR holds that meanings consist of truth conditions, so sentences really refer to their apparent (material and/or unobservable and/or objective) referents.

It might be objected that verificationism is not an "as if" position: in fact, Michael Dummett took the cue for his verificationism (subsequently adopted by Putnam) from intuitionism in the philosophy of mathematics. Moreover, intuitionism seems a form of verificationism, because it holds that theorems are true if and only if they are proved, and false if and only if their negation is proved. However, for intuitionists mathematical entities constructed

\footnotetext{
${ }^{9}$ In their famous debate on protocols of 1931-1932 Schlick argued for the former, and Neurath for the latter. Carnap originally sided with Schlick, later concluding that both views were conventionally acceptable.

${ }^{10}$ Insisting that the conditions in which a sentence $S$ is assertible are still objective states of things would be going back to a verificationism with a "basis of hard facts". Putnam's verificationism "all the way down" presupposes that although the assertibility of $\mathrm{S}$ in any particular circumstance depends on the current state of things, there is no set $\mathrm{C}$ of objectively described states of things such that $\mathrm{S}$ will always be considered assertible exactly when a member of $\mathrm{C}$ obtains.
} 
by acceptable methods are real and mathematical theorems proved by acceptable methods are true. Therefore their discourse about mathematics is not "as if", hence-the objection concludes-verifcationism is not an "as if" position. ${ }^{11}$

Nonetheless, intuitionism differs in an important sense from verificationism: in factual knowledge verification conditions fall short of truth conditions in principle; therefore if meaning consists of verification conditions (as verificationists believe) uttering ' $S$ ' actually means that ' $\mathrm{S}$ ' is verified, confirmed, or assertible, not that $\mathrm{S}$, nor that ' $\mathrm{S}$ ' is true. Hence language does not speak of its apparent referents. Instead, in formal knowledge, like mathematics, proving that $S$ in principle guarantees that ' $S$ ' is true; therefore saying that ' $S$ ' is proved is nothing less than saying that $S$, i.e., that ' $S$ ' is true. Therefore by identifying truth with proof in mathematics one does not speak "as if", but by extending this identification to factual discourse one does. Since all forms of verificationism reduce meaning to conditions which fall more or less short of truth, they are "as if" positions, but intuitionism is not, because it is not a form of verificationism. No doubt, intuitionism is antirealist, because it denies that ' $S$ ' might be true even if not proved, and that an entity might exist even if not constructed. So, intuitionism is rather a form of ontologic antirealism, denying that mathematical entities exist and have certain properties objectively (i.e., denying OR3 and OR6 on mathematical entities).

All forms of verificationism entail that the ontologic realist claims (as well as their negations) are inexpressible, and the sentences OR1-OR6 which purportedly express them are not false, but meaningless: since we cannot actually speak about $\mathrm{X}$, we cannot make any meaningful claim about either X's existence or properties. Therefore ontologic MR presupposes semantic MR.

However, verificationists grant that sentences like OR1-OR6 are perfectly meaningful and quite possibly true, once reinterpreted in what they take to be their correct meaning. For instance, Schlick held phenomenist verificationism, but he claimed that 'There exists a castle in the park' is meaningful and true in the sense that we do have a number of castlelike sensations. He also granted that.

(T) That castle was there tonight even when nobody observed it

is meaningful and true, hence also its consequence

\section{That castle exists mind-independently}

is meaningful and true, in the sense that (a) we had castle-like sensations yesterday; (b) we had perfectly similar castle-like sensations this morning; (c) in the past we never witnessed castle-like (or generally material-like sensations) disappearing and then reappearing in a few hours, except in concomitance with bombing-like sensations or similar; and in particular (d) we never witnessed castle-like (or generally material-like sensations) disappearing in concomitance with sentient-beings-going-away-like sensations. Therefore, $(\mathrm{T})$ and $\left(\mathrm{T}^{\prime}\right)$ are true, but they do not speak about the castle, only about sensations (a)-(d) (Schlick 1932b, 50, passim). By the same token Carnap (1936, 87-88) and Schlick (1936, 367-368) claimed that sentences like

${ }^{11}$ I owe this objection to an anonymous referee. 
(S) If all minds should disappear from the universe, the stars would still go on in their courses

and therefore also

\section{$\left(\mathrm{S}^{\prime}\right) \quad$ Stars exist mind-independently}

are verifiable, hence are meaningful, but only in a sense analogous to (a)-(d). ${ }^{12}$ According to Schlick the sentence 'the world will continue to exist after my death' is empirically confirmed, and "the mistake of the solipsist or idealist consists in rejecting this empirical [i.e., verificationist] interpretation and looking for some metaphysical issue behind it; but all their efforts to construct a new sense of the question end only in depriving it of its old one" $(1936,368)$.

For phenomenist verificationists our sentences actually refer to sensations, while for reductionist verificationsts they refer to observable states of things (even if those sentences apparently concern $u e$ ): there follows that the sentence OR2 no longer expresses the claim that that X (e.g. the WorlD) is irreducible, while OR5 no longer expresses the claim that X has irreducible properties, and these claims become inexpressible. For assertibility verificationists our sentences do not refer to objective states of affairs: this entails that the sentence OR3 no longer expresses the claim that X (e.g. the WorlD) is objective, while OR6 no longer expresses the claim that $\mathrm{X}$ has objective properties, and these claims become inexpressible. Thus, in general, verificationism makes metaphysical claims inexpressible.

\subsection{Epistemic Claims}

The third kind of realist claims is epistemic: these claims hold that the existence and/or the properties of $X$ can be known. Since knowledge consists of justified true beliefs, ${ }^{13}$ knowing $\mathrm{X}$ entails having beliefs about $\mathrm{X}$, which in turn entails being able to refer to $\mathrm{X}$, either in the trivial or in the realist sense. Further, the truth of beliefs may be understood either in the classic sense of the correspondence with facts ( ${ }^{C}$ truth), or in some weaker epistemic sense $\left({ }^{E}\right.$ truth), like verification, high confirmation, assertibility here and now, assertibility at the ideal limit of research, coherence with other claims, or pragmatic success. Thus, we can distinguish strong knowledge ( ${ }^{S}$ knowledge), which entails realist reference and truth as correspondence ( ${ }^{C}$ truth), and weak knowledge $\left({ }^{W}\right.$ knowledge), which requires merely trivial reference and epistemic truth $\left({ }^{E}\right.$ truth $)$. Accordingly, one can hold either

strong epistemic realism: $\mathrm{X}$ and/or its properties can be known in the strong sense $\left({ }^{S}\right.$ known $)$,

or

weak epistemic realism: $\mathrm{X}$ and/or its properties can be known in the weak sense $\left({ }^{W}\right.$ known $)$.

\footnotetext{
12 Alai (2016, 43). See also Carnap (1963 § 4A, 1967b, p. xi).

13 This is the classic conception knowledge, which I will follow here not only for the sake of simplicity and because it has been accepted for centuries, but also because it can still be defended, even in the face of Gettier's objections and the ensuing debates: see Alai (2015).
} 
When $\mathrm{X}$ is the WorlD, strong epistemic realism counts as epistemic MR, which is rejected by Kant, idealists and constructivists, who accept only weak epistemic realism. However, both epistemic MR and MAR are compatible with both epistemic realism and antirealism on some special targets. For instance, epistemic MR is compatible with believing that ue cannot be ${ }^{\mathrm{S}}$ known or that they cannot be known at all, even if other things can (i.e., epistemic MR is compatible with epistemic SAR). Conversely, epistemic MAR is compatible with believing that $u e$ can be ${ }^{\mathrm{W}}$ known as much as other things (i.e., it is compatible with epistemic SR).

Since ${ }^{S}$ knowledge entails actual realist reference, epistemic MR entails semantic MR. Moreover, as noted, ontologic MR presupposes semantic MR, because verificationism makes ontologic claims inexpressible. On the other hand, since ${ }^{S}$ knowldge entails ${ }^{C}$ truth (i.e., ${ }^{\mathrm{S}}$ knowledge is factive), claims to ${ }^{\mathrm{S}}$ know entail corresponding ontologic claims:

1. that $\mathrm{X}$ is ${ }^{\mathrm{S}}$ known to exist entails that (OR1) $\mathrm{X}$ exists

2. that $\mathrm{X}$ is ${ }^{\mathrm{S}}$ known to exist irreducibly or objectively entails that $\mathrm{X}$ exists irreducibly (OR2), or objectively (OR3), respectively.

3. that $\mathrm{X}$ is ${ }^{\mathrm{S}}$ known to have irreducible or objective properties, entails that $\mathrm{X}$ has irreducible (OR5) or objective properties (OR6), respectively.

4. that X's properties are Sknown to be so and so entails that they are so and so.

5. that X's properties are ${ }^{S}$ known to be irreducibly or objectively so and so entails that they are irreducibly or objectively so and so, respectively.

In particular, a claim to ${ }^{S}$ know that $\mathrm{X}$ is metaphysically real (ontologically, semantically and/or epistemically) entails MR about X. Obviously the same does not hold for ${ }^{\mathrm{W}}$ knowledge, and the converse of implications 1-5 does not hold either. However, by Grice's (1975) "conversational maxims" one is not supposed to assert that $S$ unless one believes that $\mathrm{s}$ /he knows that $\mathrm{S}$ (i.e., unless $\mathrm{s} / \mathrm{he}$ believes that ' $\mathrm{S}$ ' is true and that $\mathrm{s} / \mathrm{he}$ is justified in believing it). Therefore the assertion that $\mathrm{S}$ pragmatically implicates that the subject knows that $\mathrm{S}$. In everyday discourse, or for practical purposes, it might be pragmatically correct for a subject to assert that $\mathrm{S}$ without believing that $\mathrm{s} / \mathrm{he}{ }^{\mathrm{S}}$ knows that $\mathrm{S}$, but only that

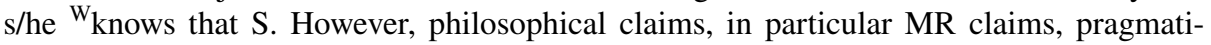
cally implicate ${ }^{\mathrm{S}_{k}}$ nowledge, because if one believed simply that s/he ${ }^{\mathrm{W}_{\mathrm{knew}}}$ about X, s/he couldn't trust that his/her knowledge actually concerned X rather than some verificationist surrogate of it, or that it concerned the objective properties of $\mathrm{X}$ rather than merely some subject-dependent properties of X.

\section{Scientific Realism and Ontologic or Semantic Metaphysical Antirealism}

Now I shall examine some typical ways in which SR is consistently held together with MAR (or simply without MR). For example, Berkeley took a metaphysically antirealist but empirically realist stand about oop (ordinary observable objects and properties), denying that they exist mind-dependently, i.e., irreducibly (OR2), but granting that they exist (OR1) in a mind-dependent way, as sets of actual or possible sensations (APS). We call this "phenomenism" about oop. Could one do the same with ue? That is, could one hold both that the physical world is mind-dependent (ontologic MAR) and that $u e$ 
and their properties exist, at least as sets of APS? It seems that this wouldn't be possible, because ue cannot be sensed: we have oop-sensations, but no ue-sensations.

Perhaps, however, both the existence of $u e$ and their irreducibility and objectivity (i.e., ontologic SR) can be joined with semantic MAR, more or less as neopositivists did with the existence of oop like a castle or the stars: one can accept the sentences 'ue exist' and ' $u e$ exist objectively and mind-independently' but interpret them verificationistically. Thus one would simply assert the obtaining of the verification conditions of those sentences-i.e., of certain sets of APS (according to phenomenists) or of certain observable states of things (according to reductionists) or of certain assertibility conditions (according to assertibility verificationists). One would then add (as Schlick did in the above quotation) that any effort to give those sentences a different realist sense would be in vain.

It might be objected that this would no longer be a form of SR but rather a form of positivism or instrumentalism, for it would reduce ue to sets of APS or to oop or to assertibility conditions. However, this would be considered a form of SAR only from the currently more common metaphysical realist conception of the oop, because from such a viewpoint reducing the ue to sets of APS or to oop or to assertibility conditions would make them less real than the oop. However, if one is verificationist across the board this objection loses it bite.

Moreover, in defence of the co-tenability of ontologic SR with semantic MAR, one might notice that any claim about $u e$ is verified (or confirmed) not just by one experiment, but by an open number of different possible experiments and observations; hence, its meaning does not consist of just one set of APS or one observable state of things, but in many sets of APS or actual or possible states of things; moroever, such sets are not reducible to their members, therefore speaking of any $u e$ in this way is not speaking only of sensations or of observable states of things.

Still, there is a problem: this strategy identifies ue with sets of actual and merely possible (i.e., counterfactual) sensations or observable states of things-but how could verificationists account for modalities and counterfactuals? As pointed out by Dummett (1959), counterfactual claims need categorical truthmakers, and in this case the most obvious candidates are categorical statements about mind-independent and irreducible $u e$. For instance, part of the verificationist meaning of 'there are charged particles in this apparatus' is that if I were to run certain experiments I would get certain observable results. But what makes this counterfactual conditional true or false, except the actual existence or non-existence of those particles?

An answer in the neopositivist vein is that possible and necessary are that which is allowed and prescribed, respectively, by empirically confirmed laws (i.e., what happens in some and all, respectively, state descriptions compatible with empirically confirmed laws). Thus, talk of ue is grounded in confirmed empirical laws, just as it was Schlick's and Carnap's the talk of so-called "mind-independent" physical bodies in the previous examples of the castle and the stars.

To this one might rejoin that empirical laws are confirmed just by past sensations or observations, hence for verificationists they are nothing but descriptions of those sensations or observations; therefore, again, ue are ultimately reduced to sensations or observable states of things. Once more, however, verificationists could reply that what confirms those laws, what constitutes their meaning, is not any single set of sensations or observations, but very complex sets of sets thereof. Therefore even ue are not completely reducible to any one set of sensations or observable conditions, and this counts as an (albeit weak) form of realism about them. 
In fact, in Testability and Meaning (1936) Carnap showed that no number of claims about APS can exhaust the meaning of one claim about oop, and in The Theoretician's Dilemma (1958) Hempel showed that discourse about ue is not reducible to discourse about observable states of things. This raises a very serious concern about verificationism, for if the meaning of discourse about oop transcends sensations, which supposedly provide its verification or confirmation conditions, and if the meaning of discourse about ue transcends possible observations, which supposedly provide its verification or confirmation conditions, it becomes unclear why and how meaning should consist of verification or confirmation conditions. Aside from this concern, however, so far we haven't found any conclusive argument against the compatibility of verificationist MAR and ontologic SR.

Another way to join SR with MAR might be this: supposed an idealist held either that the WorlD exists and has properties only in thought (like Hegel), or that only abstract entities really exist (like Plato). Then in the first case s/he could claim that $u e$ exist (merely) as models created by scientists and existing in their minds (i.e., as creatures of Popper's (1978) "World 2"), and in the second case that they exist in the realm of abstract entities (i.e., as creatures of Popper's "World 3"). Admittedly, by our prevailing standards this would be a rather weak kind of acceptance of $u e$; yet, it would still be a form of SR if s/ he claimed that these models are robust and stable constructions, since they are postulated by well confirmed theories, and they (or approximately similar models) will be preserved throughout the future developments of science. This claim, in fact, would be challenged by scientific antirealists, on the grounds that (a) because of empirical underdetermination these models cannot be sufficiently well confirmed, and (b) they are not stable, since the pessimistic meta-induction shows that current theories will be abandoned in the future. Thus, in the face of such a SAR, the claim that $u e$ are robust and stable constructions would be a form of SR.

Summing up, we have seen how certain instances of ontologic SR can be consistently held in conjunction with certain forms of MAR. These are just some possible examples of joint SR and MAR, and probably other examples are possible. A fortiori, it would certainly be consistent to hold SR while simply remaining agnostic about MR. However, now we shall see that such a position would be very hard to defend, and scientific realists may almost be compelled to accept MR.

\section{Metaphysical Antirealism and the "No Miracle" Arguments}

Putnam claimed that realism "is the only philosophy that doesn't make the success of science a miracle" $(1975,73)$, and the inference from the need to explain the success of theories (especially their novel predictive success) to their (approximate) truth is commonly called the "no miracle argument" (NMA). The NMA has been employed by a number of authors and considered "the ultimate argument for scientific realism". ${ }^{14}$ In Sect. 4.3 I shall point out that it simultaneously supports MR. I will also consider three strictly related inferences which do not take as explanandum specifically the success of science and as explanans SR, but take as explanandum certain basic phenomena about the physical world and knowledge in general, and as explanans both SR and MR. However, they too deserve to be called "NMA", because they argue that the explanandum would be a miracle without

${ }^{14}$ Musgrave (1988). See also Alai (2014a, b). 
the explanans, and scientific realists could hardly use the usual version of the NMA while rejecting these versions.

\subsection{The NMA from the Stability and Continuity of Sensations}

One of these other versions of NMA is the "no miracle argument from the order of sensations" $\left(\mathrm{NMA}^{\mathrm{OS}}\right)$. I will argue that it refutes not only Berkleyan phenomenism (the metaphysical antirealist claim that the physical world is mind-dependent), but also phenomenist verificationism, which as we saw can be consistently combined with ontologic SR.

The NMA $^{\mathrm{OS}}$ considers two explananda: first, certain sensations are constantly accompanied by certain others (for instance, the shape, color, taste and scent of peaches; or the shape, color, taste and scent of lemons.). Second, sensations are usually stable or change gradually. For instance,

I. I bake in the sun on the beach; the temperature is pleasantly warm

II. In the night I am awake in my bed, in the dark; I see only black and hear nothing

III. A distant car is approaching. Its image constantly grows larger in my visual field by $1 / 10$ per second
If I don't move, after 1" my sensations are identical or imperceptibly different (I don't feel hot, don't shiver with cold, etc.)

If I turn my head $45^{\circ}$, no sensation changes: I don't see any color or light, I don't hear any sound, etc.

After $1^{\prime \prime}$ it is $1 / 10$ larger, after $2 "$ it is $2 / 10$ larger, after $3^{\prime \prime}$ it is $3 / 10$ larger, etc.

IV. Moreover, these sensations are shared intersubjectively.

Common sense unconsciously postulates oop to account for the order, stability and continuity of sensations (OS). Physics, physiology and neuroscience also explain the OS by appealing to oop. But if the physical world were mind-dependent, i.e., if there were just sensations, why would they be so stable and orderly? If they had no causes they should be random: why in the next second should I have exactly the same sensation or one imperceptibly different, rather than any of, say, 10,000 possible different sensations? If sensations were mutually independent, the chance of having a smooth sensorial experience for $1^{\prime}$ would be $1 / 10,000^{60}$, so it should never actually happen in my lifetime; yet it happens all the time. Why? If sensations had no common causes, it would be even less likely for them to be shared. The only non-miraculous explanation, concludes the $\mathrm{NMA}^{\mathrm{OS}}$, is that there are mind-independent oop. ${ }^{15}$

Phenomenists may reply that each one of the $10,000^{60}$ series that are possible in $1^{\prime}$ has the same probability, and one of them has to take place, so no wonder if just the one we experienced (the continuous one) took place. But if sensations were random, it would be overwhelmingly probable that in the next minute we would have a different series, and that the series would change, perhaps even wildly, every minute. Instead we most often experience the same series for many minutes in a row. That is, if sensations were random and I were lying in bed in the dark, the probability that in the next second I would have the same sensations would equal the probability that instead I would have sensations like baking in the sun, or sitting in the midst of a volcanic eruption or anything else. So, the phenomenist's incapacity to explain OS is also an incapacity to make predictions. Berkeley explained

${ }^{15}$ See also Musgrave (1993, ch. 7, § 4) and Alai (2014c, 112). 
all this by God's miracle. But if we exclude miracles, the only explanation is the mindindependent reality of oop. Thus the $\mathrm{NMA}^{\mathrm{OS}}$ refutes Berkleyan phenomenism. ${ }^{16}$

Can phenomenist verificationists do any better? They might explain the OS by holding that sensations are caused by ordered and stable oop. For them, though, talking of oop is just talking of regular patterns of sensations. Therefore they will not explain the OS, but simply restate that sensations are ordered and stable. It might be observed that oop do not consist only of ordered and stable sensations, but also of regularly discontinuous sensations; but I will discuss this with the next form of NMA. Verificationists might also insist that talking of oop is talking of sets of actual and possible sensations, so actual ordered and stable sensations are explained by appeal to possible sensations. But they understand possibility in terms of confirmed empirical laws, whose content is just the past sensations by which laws are confirmed; therefore again explanations by possible sensations are nothing more than generalized descriptions of observed phenomena.

Therefore, in order to explain the OS we need to assume the existence of oop without any verificationistic reinterpretation. Thus, the $\mathrm{NMA}^{\mathrm{OS}}$ refutes phenomenist verificationism, a form of MAR with which SR can be coherently associated, as we saw in Sect. 3.

Yet, SR might also be associated with reductionist and assertibility verificationismand with further forms of MAR (as we shall see in more detail in Sect. 5). Moreover, the $\mathrm{NMA}^{\mathrm{OS}}$ is not the version of NMA generally used to support SR; therefore scientific realists might try to save phenomenism and phenomenist verificationism by rejecting it. The $\mathrm{NMA}^{\mathrm{OS}}$ has the same structure as the usual NMA, viz. the inference to the only non-miraculous explanation; hence between rejecting the former and using the latter there can be some methodological inconsistency, but there is no strict contradiction. Up to this point, therefore, we have no conclusive argument against the co-tenability of SR and MAR. Greater difficulties, however, come with another version of the NMA.

\subsection{The NMA from Regular Discontinuities}

Obviously oop undergo regular changes; they behave regularly, i.e., they obey laws. In phenomenistic terms, this is to say that sensations display not just continuity, but also regular discontinuities: liquid water regularly and invariantly becomes solid at $0^{\circ}$, and it becomes gaseous at $100^{\circ}$ (in phenomenistic terms liquid-water sensations always turn into ice sensations in concomitance with $0^{\circ}$ sensations; etc.). As remarked by Kant (1781-1787, 1083 [A765/B793]), sunlight softens wax, but it hardens clay: always so, never the opposite. Fire regularly burns wood, not metals; iron filings regularly follow certain patterns around a magnet, etc. Moreover, minds have no influence on these changes which might account for their regularity.

Science explains the regularity of change by claiming that there are $u e$, and it explains the phenomenological laws governing change by constructing theories which describe the nature and behavior of those $u e$. The capacity of theories to explain phenomenological laws speaks for their truth, but this is a simple inference to the best explanation, not a NMA: for instance, it would not be a miracle that water becomes solid at $0^{\circ}$ and gaseous at $100^{\circ}$, etc., if the kinetic molecular theory of matter states was false, for there would be a different true

\footnotetext{
${ }^{16}$ Granted, there may be another way to resist phenomenism, i.e., arguing for direct realism. But if the realist is not a direct realist, or s/he cannot persuade phenomenists to accept this view, s/he can at least argue for indirect realism through the $\mathrm{NMA}^{\mathrm{OS}}$.
} 
theory to explain it. However, if $u e$ didn't exist at all, we would be left without any explanation for these regular changes. So, this argument can be used as a NMA from regular discontinuities $\left(\mathrm{NMA}^{\mathrm{RD}}\right)$ for the existence of $u e$.

In contrast, Berkelyan phenomenism cannot offer a non-miraculous explanation of regular discontinuities, because on the one hand it doesn't admit the existence of $u e$, as we saw-and on the other hand it has no other explanation of observable regularities, except God's miracle.

As for verificationists, of course they accept the letter of the scientific account, but in their re-interpretation it loses all its explanatory power. In fact, for phenomenist verificationists talk of $u e$ is just talk of sets of APS, while for reductionist verificationists it reduces to talk about oop. Therefore these kinds of verificationists cannot explain the regular discontinuities in the behavior of oop by appeal to ue: although their account literally sounds like an explanation of observable regularities in terms of unobservable regularities, it is actually just a redescription of those same observable regularities.

Assertibility verificationists cannot explain regular discontinuities either, because for them talking of $u e$ is just talking of the (inter)subjective conditions in which $u e$-sentences are assertible. That is, for them to say "There is a magnetic field here and now" (or "An atom has decayed here and now", etc.) means simply "Asserting that there is a magnetic field (or that an atom has decayed, etc.) here and now is licensed by the rules governing assertions in scientific and more generally linguistic practice". In substance, this is like saying "Everything is as if there were a magnetic field here and now", or "Everything is as if an atom had decayed here and now". But as pointed out by Musgrave (2006-7), "There is a magnetic field" explains why the iron filings produce a certain pattern, but "It is as if there were a magnetic field" does not. Objective states of things explain, while epistemic or (inter)subjective states do not, since it might be assertible that there is a magnetic field, even if there is none; moreover, even if the magnetic field is there, iron filings produce a certain pattern because the magnetic field is there, not because it is assertible that it is: our linguistic practices have no causal influence on reality.

As before, verificationists might reply that speaking of a certain kind of $u e$ is speaking of a very large and probably open number of observable regularities (all those in which ue of that sort are supposed to play a causal role). Therefore, even when verificationistically reinterpreted, talking of ue effectively explains phenomena because it accounts for each particular regularity by appealing to a whole set of regularities.

However, unless the $u e$ in question are taken seriously as something more than and different from those observable regularities, there is nothing that links any one of these regularities to all the others, so one of them cannot be explained by all the others. For instance, we explain that water freezes at $0^{\circ}$ because at $0^{\circ}$ molecules have such and such mean kinetic energy, etc. But if 'molecules' is reinterpreted in terms of observable regularities, this explanation amounts to saying that water freezes at $0^{\circ}$ because water freezes at $0^{\circ}$, and it boils at $100^{\circ}$, and wood burns, and metals melt, and so on for all regularities which are usually accounted for by molecules.

Thus the $\mathrm{NMA}^{\mathrm{RD}}$ establishes the existence of $u e$ and refutes verificationism in one fell swoop. ${ }^{17}$ Therefore scientific realists who use it must accept semantic MR. In order to avoid MR they must not only support the existence of $u e$ without using the $\mathrm{NMA}^{\mathrm{RD}}$, but also reject the $\mathrm{NMA}^{\mathrm{RD}}$, which is quite difficult-especially if they simultaneously use the

$\overline{17}$ This argument is closely related to that in Putnam (1978b, 107-111). 
standard form of the NMA (se Sect. 4.2). But again, without the standard NMA they could hardly resist the antirealist arguments from empirical underdetermination and pessimistic meta-induction. Therefore the conjunction of scientific realist existence claims with semantic MAR (or with semantic agnosticism), even if logically coherent, is indefensible.

\subsection{The NMA from Novel Predictions}

The standard version of the NMA argues that SR is the only non-miraculous explanation of the success of science, especially of its predictive success. Therefore I shall call this version "no miracle argument from novel predictions" $\left(\mathrm{NMA}^{\mathrm{NP}}\right)$. The $\mathrm{NMA}^{\mathrm{NP}}$ is stronger than the $\mathrm{NMA}^{\mathrm{RD}}$, because it shows that the success of novel predictions would be a miracle not only if ue didn't exist (like the $\mathrm{NMA}^{\mathrm{RD}}$ ), but also if our theories about them were substantially false.

The NMA ${ }^{\mathrm{NP}}$ contends that theories make predictions which, in addition to turning out true, are so bold (precise and informative, i.e., a priori improbable) and so different from everything we know that one would consider them unpredictable; therefore it would be a miracle if theories were not at least approximately true. Newton's gravitation theory predicted the existence and orbit of Neptune, Mendeleev's periodic theory predicted the existence and properties of new chemical elements, the atomic theory predicted the incredible power of atomic energy, Special Relativity predicted the retard of clocks in motion, General Relativity predicted the gravitational lens, and the Big Bang theory predicted the background radiation. These are just some of the most startling instances of novel predictions.

Antirealists may object that it is no wonder that a certain theory $\mathrm{T}$ (together with various auxiliary assumptions $\mathrm{A}_{1} \ldots \mathrm{A}_{\mathrm{n}}$ ) entails a certain novel prediction $n p$, since entailment is simply a matter of logic; nor do we need to explain why $n p$ is true, for that is simply because of the way the world is. Moreover, the fact that $\mathrm{T}$ has a true consequence does not show that $\mathrm{T}$ is true, because false theories can have true consequences. In fact, since for any subject the truth is one and the falsities are countless, among the theories entailing $n p$ for any true one there are many more false ones, hence the chance is that $\mathrm{T}$ is false.

However, it is also the case that for any false theory that entails $n p$ there are countless more that do not: the more a prediction is bold and improbable, the fewer the possible false theories entailing it. Therefore, if theories were picked randomly, in typical cases the chance to get a false theory entailing such a prediction would be practically null. For instance, the magnetic moment of the electron was predicted by quantum electrodynamics to be $1.159652359 \times 10^{-12}$, and eventually found to be $1.159652410 \times 10^{-12}$ : the chance of getting such an extraordinary precision was as low as $5 \times 10^{-8}$ (Wright 2002, 143-144).

Hence, it would be a miracle if by chance scientists had found a false theory entailing $n p$. The only non-miraculous explanation is that the theory $\mathrm{T}$ actually implying $n p$ was found not by chance, but on purpose and by a reliable method. How is this possible? Again, the only possible answer is that (a) scientists look for true and informationally rich theories, (b) the scientific method allows such theories to be discovered sufficiently often, and (c) in the case at hand they found one informationally rich enough and close enough to the truth to entail $n p .^{18}$

This explanation can be further detailed as follows: a novel phenomenon $n p$ is typically predicted by $T$ with the help of a number of auxiliary assumptions $A_{1} \ldots A_{n}$, which in

$\overline{18}$ White (2003, 659-664) and Alai (2014a, 299-300, 2014b, 113-114). 
turn are the consequences of a number of accepted theories $T_{1} \ldots T_{n}$. Each of these theories $\mathrm{T}, \mathrm{T}_{1} \ldots \mathrm{T}_{\mathrm{n}}$ was built to account for a different body of previously known phenomena $\left(\mathrm{KP}, \mathrm{KP}_{1} \ldots \mathrm{KP}_{\mathrm{n}}\right.$ respectively). Moreover, $\mathrm{T}, \mathrm{T}_{1} \ldots \mathrm{T}_{\mathrm{n}}$ are mutually independent and often from different disciplines. ${ }^{19}$ The known phenomena $\mathrm{KP}, \mathrm{KP}_{1} \ldots \mathrm{KP}_{\mathrm{n}}$ are also from disparate domains and very different, not only among themselves, but also from $n p$ : they are so different that per se they do not suggest $n p$ or give it any likelihood. How, then, does it happen that $\mathrm{T}$ with $\mathrm{A}_{1} \ldots \mathrm{A}_{\mathrm{n}}$ predicts precisely $n p$, rather than any of the infinitely many potential but unreal phenomena $\operatorname{potp}_{1} \ldots$ potp $_{\infty}$ ?

\section{PHENOMENA}
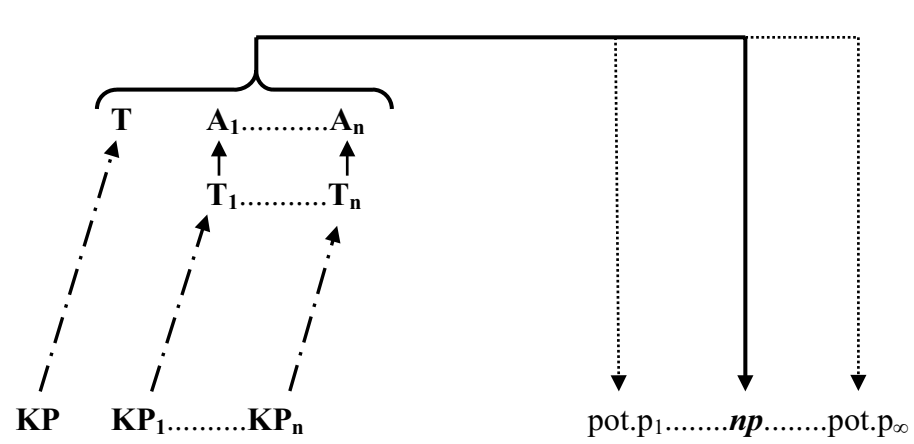

The only non-miraculous answer is that $T, T_{1} \ldots T_{n}$ are at least partly correct descriptions of unobservable systems US, $\mathrm{US}_{1} \ldots \mathrm{US}_{\mathrm{n}}$ which individually cause the known bodies of phenomena $\mathrm{KP}, \mathrm{KP}_{1} \ldots \mathrm{KP}_{\mathrm{n}}$ respectively, and jointly cause the novel phenomenon $n p$ (Alai 2014a, 316-318).

${ }^{19}$ See Kosso (1992, ch. 9). 


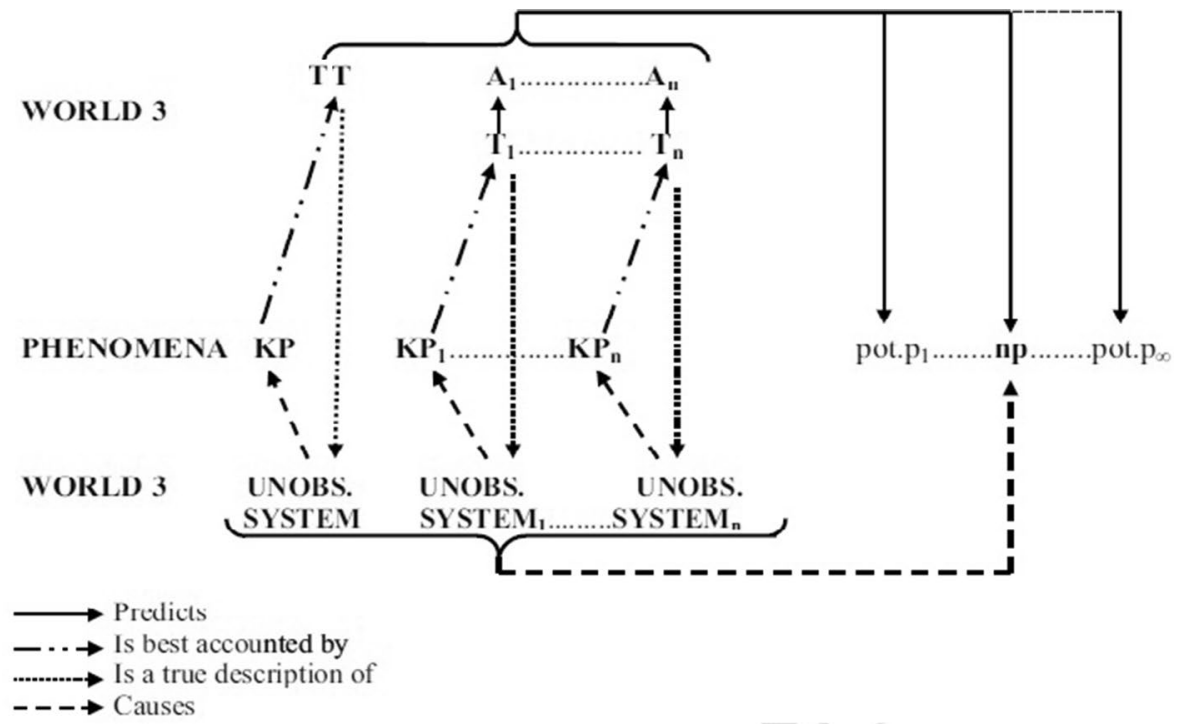

Verificationsts cannot reproduce this explanation, because if $T, T_{1} \ldots T_{n}$ are reinterpreted verificationistically, they simply describe the bodies of phenomena $K P, K_{1} \ldots \mathrm{KP}_{n}$ which confirm them (for reductionist verificationism), or the corresponding sensations (for phenomenist verificationism). However, since those phenomena are so different from $n p$, there would be no reason why the conjunction of their descriptions implied $n p$. Instead, for assertibility verificationists $\mathrm{T}, \mathrm{T}_{1} \ldots \mathrm{T}_{\mathrm{n}}$ simply say that it is assertible that the unobservable systems US, $\mathrm{US}_{1} \ldots \mathrm{US}_{\mathrm{n}}$ exist. In practice, they say that everything is as if those systems were real. But if US, $\mathrm{US}_{1} \ldots \mathrm{US}_{\mathrm{n}}$ were not actually there to jointly cause $n p$, it would remain a miraculous coincidence that $n p$ actually took place as predicted by $\mathrm{T}$ and $\mathrm{A}_{1} \ldots$ $\mathrm{A}_{\mathrm{n}}$.

Thus, successful novel predictions can be explained only by claiming that successful theories are basically right about $u e$, and by interpreting this claim realistically (i.e., by SR plus semantic MR). Therefore the $\mathrm{NMA}^{\mathrm{NP}}$ too supports both scientific realism and semantic metaphysical realism at once, so forbidding SR from joining with MAR or with agnosticism. If one tried to reject the $\mathrm{NMA}^{\mathrm{NP}}$ in order to preserve agnosticism or MAR, then one couldn't use it to support SR. Hence, SR without MR, albeit coherent, is indefensible. ${ }^{20}$

\section{Scientific Realism and Epistemic Metaphysical Antirealism}

Ontologic MR holds that things have objective properties, relations, nature, structure or constitution (in short, properties). 'Objective' means that these properties are what they are independently of the knowing subject: they are not just a product of the sensations, perceptions, conceptualizations or thoughts by which they are apprehended. Moreover, epistemic

${ }^{20}$ See also Musgrave (1993 ch. 7 § 4). 
MR holds that we can ${ }^{S}$ know those objective properties, where 'S know' entails that our beliefs actually refer to things and are true in the correspondence sense. As pointed out above, epistemic MR entails ontologic MR, and it amounts to claiming that we can know how things are "in themselves". Epistemic MAR is often (appropriately enough) called "constructivism", for it holds that theories and descriptions are our own "constructions", which do not stand in a correspondence relation to the independent properties of things

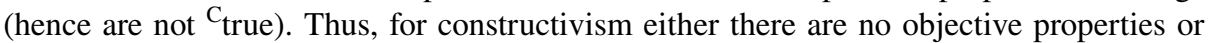
they cannot be ${ }^{S}$ known. This is why for Putnam $(2012,101)$ the second component of MR is the denial of "conceptual relativity" (i.e., of constructivism). The question is: Can one consistently hold SR without holding epistemic MR, or even straightforwardly embracing constructivism? Further, could one defend such a joint position?

There are basically two arguments for constructivism: one from perception and conceptualization, and one from verificationism. The former was employed in different forms by Kant, Puntam and Goodman. They argued that the subjective input to knowledge, already in perception, but more importantly in conceptualization, is inextricable from the objective input. Thus, besides perceiving things with properties that they do not have in themselves, in thought we carve things up and arrange them into relations (of space, time and perhaps others) in ways which do not correspond to how they are carved out and related in themselves. ${ }^{21}$ This is to say that the properties of known things (of things as we know them) are not objective, but just (inter)subjective.

The argument from verificationism has been used by Putnam, couched in his "ideal assertibility" version of verificationism: according to it to say that subject $s$ has property $\mathrm{P}$ actually meant that it is ideally assertible that $s$ has P: i.e., that at the ideal limit of research it will be appropriate by the rules governing our linguistic practice to assert that $s$ has $\mathrm{P}$. It follows that language cannot speak of anything objective, but only of (inter)subjective ideal assertibility conditions ${ }^{22}$; it cannot say that things are so and so, but that at the ideal limit of research everything would be $a$ s if things were so and so. Therefore even if things have objective properties we can't refer to them or describe them. Hence objective properties cannot be ${ }^{\mathrm{S}}$ known, nor claimed to be ${ }^{\mathrm{S}}$ known, hence epistemic MR is both false and inexpressible. $^{23}$

Whichever argument is used, constructivism is compatible with the non-metaphysical claim that things can be ${ }^{\mathrm{W}_{\mathrm{k}}}$ nown, in the sense that we can have beliefs about the (inter)subjective properties of things, and those beliefs can be well confirmed, intersubjectively valid and stable, i.e., at least approximately (ideally) assertible. ${ }^{24}$ For Kant this held because our perceptual and conceptual schemes are valid and compelling for all human beings; for later authors this holds because, although conceptual schemes may change, given any one conceptual scheme, everybody must agree to the well founded claims made within that scheme (this is why Putnam termed his position "internal realism”).

\footnotetext{
21 If in themselves they are carved out or related in any way at all (Alai 1994, 65-72). For Kant things are necessarily rearranged in this subjective way because otherwise we couldn't have synthetic a priori judgments. For Putnam's argument see (1977, 130-135, 1978c). For Goodman's argument see (1978, chs. 2, 7). See Alai (1994, ch. 3).

22 See footnote 10.

23 Putnam calls it "incoherent" and "unintelligible". Verificationism in turn is supported by the "model theoretic" argument against realist reference (Putnam 1977, 124-130, especially 127, 1981, ch. 2, 3).

${ }^{24}$ In fact, Kant claimed that knowledge is “objective" just by weakening the sense of 'objective' to mean precisely these epistemic virtues: Kant (1783, § 18 (IV, 298)) and Agazzi (2014, 51-57).
} 
Putnam joined constructivism (epistemic MAR) with SR by holding that although we cannot ${ }^{\mathrm{S}}$ know anything, we can ${ }^{\mathrm{W}}$ know $u e$ (just as we know oop and possibly other things): that is, we can build theories that are at least approximately true in some epistemic sense of truth, i.e., well confirmed, intersubjectively valid and stable (1977, 135-138). Albeit weak, this claim about $u e$ counts as realist in opposition to a SAR holding that $u e$ cannot even be ${ }^{\mathrm{w}_{k n o w n}}$, based on the classic antirealist arguments: that theories about $u e$ are much less supported by experience than beliefs about oop; that they are empirically underdetermined, hence never sufficiently confirmed; and that the pessimistic meta-induction shows that they will all be rejected sooner or later. Thus, SR may consistently be held without epistemic MR, or be coupled with constructivist MAR; but again, we'll see that defending this sort of stand is quite another matter.

\section{Metaphysical Antirealism and Herbart's NMA}

Against Kant's constructivism Johann Friedrich Herbart used what we might call a "no miracle argument from the applicability of schemes" $\left(\mathrm{NMA}^{\mathrm{AS}}\right)$. According to Kant there is nothing in the world in itself that corresponds to our a priori forms of intuition (space and time) and thought (categories). But if Kant were right, we would be completely free to subsume any content of experience (sensation or perception) under any form at will. Instead, we always subsume them to the same forms or categories, and we feel we have no choice in this. For example, why must we necessarily conceptualize two phenomena A and B as cause and effect respectively, rather than the other way around, or as in reciprocal action, or as substance and accident respectively, or vice versa?

One might answer that our conceptualization is based on the observation that B immediately follows $\mathrm{A}$ in time and is contiguous to it in space. But for Kant time and space are also subjective forms of intuition; therefore, why do we always perceive B immediately after A, and not the other way around? Why do we always perceive B as contiguous to A, and not far apart from it? ? $^{25}$

The only non-miraculous explanation for why the world can be organized and conceptualized by us in a determinate consistent way is that it has objective features, and although they may be very different from how we experience and represent them, they supply the criteria for the application of our forms, concepts or schemes-so that conceptualization "mimics" the structure of the world (or more precisely, corresponds to it) ${ }^{26}$ Schlick also noticed that the world and our representation of it must have the same multiplicity, so that any difference in the latter must correspond to a difference in the former. This means that we can ${ }^{\mathrm{S}}$ know the world, i.e., there can be an at least structural correspondence between it and our descriptions. ${ }^{27}$ Kant himself acknowledged that the fact that the light of the Sun softens the wax but hardens the clay is something we cannot anticipate, for it must be decided by things in themselves. ${ }^{28}$

In constructing his "new riddle of induction" Nelson Goodman assumed that our concepts are utterly arbitrary collections of things, reflecting no objective similarities or

\footnotetext{
25 This is often described as Kant's "schematism" problem. See e.g. the detailed discussion in Ferraris (2004, 117-126).

${ }^{26}$ Herbart (1813, 222 ff.), Parrini (2011, 60) and Alai (2014c, 114-115, 2017, 18-19).

27 Schlick (1932a, 238) and Parrini (2011, 61).

${ }^{28}$ Kant (1781-1787, 1083 [A765./B793]), Parrini (2011, 63-64) and Alai (1994, 82-89).
} 
differences among things in themselves. Yet, his own brilliant discussion of odd predicates like 'grue' and 'bleen' implicitly shows that this has an absurd consequence: if he were right, things would suddenly change colors (and indeed any other property) without any cause, at random times, over and over. ${ }^{29}$

If conceptualization does not obey objective constraints, why is it that when we classify things (say, this thing as green, that thing as a tree) we don't feel we are acting arbitrarily? And most importantly, why do our classifications yield true predictions? For instance, if 'lemon' and 'sour' are just arbitrary collections we make, not corresponding to any subject-independent property or distinction, why whenever I classify something as a lemon do I also find that I have to classify its taste as sour? Couldn't I occasionally classify it as sweet or salty? Further, why can I trust that the same will generally happen in the future? The only explanation is that in conceptualization we are free to conventionally draw the boundaries of kinds, but we can draw them consistently only because we follow objective similarities and differences in the world itself. ${ }^{30}$

If we were utterly free to shape known reality, it would be inexplainable why reality stubbornly resists us, often surprising us and even contradicting our expectations, and why it places basically the same constraints on the behavior of creatures as epistemically different as humans, dogs, worms and ivy. ${ }^{31}$

Constructivism is also refuted by the NMA from novel predictions $\left(\mathrm{NMA}^{\mathrm{NP}}\right)$, along with phenomenism: the novel phenomenon $n p$ predicted by a theory $\mathrm{T}$ in conjunction with auxiliary assumptions derived from theories $T_{1} \ldots T_{n}$ is so different from the known phenomena $\mathrm{KP}$ and $\mathrm{KP}_{1} \ldots \mathrm{KP}_{\mathrm{n}}$ that it could not have been guessed merely by taking a cue from them. Hence novel predictions are possible only if theories are at least partially ${ }^{C_{\text {true }}}$ about certain objective unobservable mechanisms which cause the old phenomena and (as we find out) the new one. If, though, conceptualization didn't in any way correspond with objective properties of the world, theories couldn't capture those unobservable mechanisms, so novel predictions would be impossible.

This refutes constructivism (and once again verificationism, for it entails constructivism), establishing epistemic MR. Therefore SR without epistemic MR is indefensible, even if consistent. One could avoid epistemic MR by trying (I don't know how) to reject the $\mathrm{NMA}^{\mathrm{AS}}$ and the NMA ${ }^{\mathrm{NP}}$, but then one wouldn't be able to defend SR in the face of the antirealist arguments from empirical underdetermination and pessimistic meta-induction. Sankey (2008, 137-141) examines two further formulations of the NMA, also concluding that certain metaphysical assumptions are required by a realist explanation of scientific success.

\footnotetext{
${ }^{29}$ Goodman (1954) and Alai (1991).

30 Alai (1994, 2017, 9-11, 18-19, 118-148) and Eco (2012).

31 Ferraris (2012, 39-41, 48-51) and Eco (2012). For further points which are unexplainable unless our schematization of the world hinges on some of it objective properties see Ferraris $(2004,74,78,85,90$, 99-100, 115-117, passim).
} 


\section{Conclusion}

In a very conspicuous sense SR is the claim that the specific doubts concerning ue (at least prima facie different from those concerning MR) can be resisted, hence ue are ontologically, semantically and epistemically as real as anything else-i.e. enjoy the highest available degree of reality. In this sense SR and MR are logically independent. I have pointed out that this allows us to make sense of Putnam's and others' association of some typical scientific realist claims concerning existence, truth and knowledge with metaphysical antirealist doctrines like verificationism and constructivism.

However I contended that SR cannot be effectively defended without MR. In fact, I examined four forms of the NMA, arguing that none of them can support SR without also supporting MR. Scientific realists wishing to embrace verificationism or constructivism, or simply to avoid MR, should try to refute the NMA, but then they wouldn't be able to support SR. In fact, without MR, SR reduces to the thesis that scientific theories are confirmable beyond reasonable doubt and will be preserved through the future developments of science. In other words, when understood non-metaphysically, claims about the existence and properties of $u e$ simply say that theories about them are verified in some suitable sense. However, without the NMA these claims cannot be defended in the face of the antirealist arguments from the empirical underdetermination of theories and the pessimistic metainduction. Therefore, on the one hand MR is not a superfluous or merely optional addition to SR: even if not required for its consistency, it is needed to defend it. On the other hand, supplementing SR by MR has no additional argumentative costs, for the two are supported simultaneously by the same arguments.

In general, realism about $\mathrm{X}$ is the claim that $\mathrm{X}$ is really as it appears to be, in spite of possible doubts. Therefore realists must argue that the appearance is not merely an appearance-an empty or wrong semblance. However, to show that the appearance corresponds to reality - unless it is immediately obvious - one needs abduction, of which the NMA is the strongest form. As a result, the divide between realists and antirealists is marked by their attitude toward abduction, and realisms of different kinds tend to stick together, for they must fall on the same side of that divide.

Acknowledgements Open access funding provided by Università degli Studi di Urbino Carlo Bo within the CRUI-CARE Agreement. I thank Alberto Corti, Peter Vickers and the audience of the Dubrovnik Philosophy of Science Conference in 2019 for useful discussions on these topics. This work has been made possible by a leave of absence granted by the University of Urbino (Department of Pure and Applied Sciences).

Author Contributions Only one author.

Funding This work was supported by the University of Urbino through the Contributo d'Ateneo progetti PRIN2015 and the DiSPeA Research Projects 2017, and by the MIUR (Italian Ministry of Education, University and Research) through the national project PRIN 2017 "The Manifest Image and the Scientific Image" prot. 2017ZNWW7F_004.

\section{Compliance with Ethical Standards}

Conflict of interest The author declares that he has no conflict of interest.

Open Access This article is licensed under a Creative Commons Attribution 4.0 International License, which permits use, sharing, adaptation, distribution and reproduction in any medium or format, as long as you give appropriate credit to the original author(s) and the source, provide a link to the Creative Commons licence, and indicate if changes were made. The images or other third party material in this article are included in the article's Creative Commons licence, unless indicated otherwise in a credit line to the 
material. If material is not included in the article's Creative Commons licence and your intended use is not permitted by statutory regulation or exceeds the permitted use, you will need to obtain permission directly from the copyright holder. To view a copy of this licence, visit http://creativecommons.org/licenses/by/4.0/.

\section{References}

Agazzi, E. (2014). Scientific objectivity and its contexts. Cham: Springer.

Alai, M. (1991). Goodman's paradox: Drawing conclusions from a long debate. In Nuovi problemi della logica e della filosofia della scienza, Atti del Congresso S.I.L.F.S. 1990, vol. I, a cura di D. Costantini e M.C. Galavotti, CLUEB, Bologna (pp. 109-116).

Alai, M. (1994). Modi di conoscere il mondo. Milano: Franco Angeli.

Alai, M. (2014a). Novel predictions and the no miracle argument. Erkenntnis, 79(2), 297-326.

Alai, M. (2014b). Explanatory realism. In E. Agazzi (Ed.), Science, metaphysics, religion. Proceedings of the conference of the international academy of philosophy of science, Siroki Brijeg 24-24 July 2013. Milano: Franco Angeli (pp. 99-116).

Alai, M. (2014c). Realismo, idealismo e agnosticismo. Una prospettiva epistemologica. Hermeneutica (Nuova Serie) (pp. 109-126).

Alai, M. (2015). Regimenting the ordinary notions of knowledge and justification after gettier. In M. L. Bianca \& P. Piccari (Eds.), Epistemology of ordinary knowledge (pp. 247-261). Newcastle upon Tyne: Cambridge Scholars.

Alai, M. (2016). Stars and minds. Empirical realism and metaphysical antirealism in liberalized neopositivism. In L. Felline, A. Ledda, E. Rossanese (eds.) New directions in logic and the philosophy of science, SILFS (Vol. 3). College Publications, London 2016, ISBN 978-1-84890-160-5, 3-15.

Alai, M. (2017). The metaphysical scope of the new realism: Confronting Eco's and Parrini's strictures. In L. Taddio (Ed.), New perspectives on realism (pp. 9-31). Milano: Mimesis International.

Carnap R. (1928). Scheinprobleme in der Philosophie. Das Fremdpsychische und der Realismusstreit. Berlin-Schlachtensee, Weltkreis-Verlag. English transl. Pseudoproblems in Philosophy. In Carnap 1967 a.

Carnap, R. (1936). Testability and meaning. Philosophy of Science, 3(4), 419-471. Repr. in Feigl H., Brodbeck M. (eds.), University of Minnesota Readings in the Philosophy of Science (pp. 47-92). New York: Appleton-Century-Crofts, Inc.

Carnap, R. (1950). Empiricism, semantics, and ontology. Revue Internationale de Philosophie, 4, $20-40$.

Carnap R. (1963). Replies and systematic expositions. In P. A. Schilpp (Ed.), The Philosophy of Rudolf Carnap, vol. XI of Library of Living Philosophers, Open Court, Peru, Ill. (pp. 859-1013).

Carnap, R. (1967a). The Logical structure of the world and pseudoproblems in philosophy. Berkeley \& Los Angeles, CA: University of California Press.

Carnap, R. (1967b). Preface to the second edition. In Carnap R., 1967a.

Dummett, M. (1959). Truth. Proceedings of the Aristotelian Society, 59(1):141-62. Repr. in M. Dummett., M. Truth and other Enigmas, Duckworth, London 1978.

Eco, U. (2012). 'Il Realismo minimo', La Repubblica (November 3, 2012).

Einstein, A., Podolsky, B., \& Rosen, N. (1935). Can quantum-mechanical description of physical reality be considered complete? Physical Review, 47(10), 777-780.

Ferraris, M. (2004). Goodbye, Kant! Cosa resta oggi della Critica della ragion pura, Bompiani, Milano. English transl. Goodbye, Kant! What Still Stands of the Critique of Pure Reason. State University of New York Press.

Ferraris, (2012). Manifesto del nuovo realismo, Laterza, Roma Bari. English transl. Manifesto of New Realism, SUNY 2014

Goodman, N. (1954). The new riddle of induction. In N. Goodman (Ed.), Fact, fiction, and forecast (pp. 59-83). London: University of London: Athlone Press.

Goodman, N. (1978). Ways of worldmaking. Indianapolis: Hackett, Indianapolis.

Grice, H. P. (1975). Logic and conversation. In Syntax and Semantics, vol. 3, Speech Acts, a cura di P. Cole e J. Morgan. New York: Academic Press.

Hempel, C. G. (1958). The theoretician's dilemma: a study in the logic of theory construction. Minneapolis, MN: University of Minnesota Press.

Herbart, J. F. (1813). Lehrbuch zur Einleitung in die Philosophie, Unzer, Königsberg. Italian transl. Introduzione alla filosofia, Laterza, Bari 1908

Kant, I. (1781-1787). Kritik der reinen Vernunft, Preußischen Akademie der Wissenschaften. 
Kant, I. (1783). Prolegomena zu einer jeden künftigen Metaphysik, die als Wissenschaft wird auftreten können, Hartknoch, Riga.

Kosso, P. (1992). Reading the book of nature: An introduction to the philosophy of science. Cambridge, MA: Cambridge University Press.

Musgrave, A. (1988). The ultimate argument for scientific realism. In R. Nola (Ed.), Realism and relativism in science (pp. 229-252). Dordrecht: Kluwer.

Musgrave, A. (1993). Common sense, science and scepticism. Cambridge: Cambridge University Press.

Musgrave, A. (2006-2007). The 'miracle argument' for scientific realism, The Rutherford Journal 2. https://www.rutherfordjournal.org/article020108.html.

Parrini, P. (2011). Il valore della verità. Milano: Guerini.

Popper, K. (1978). Three worlds. The tanner lecture on human values. https://tannerlectures.utah.edu/_ documents/a-to-z/p/popper80.pdf.

Psillos, S.(2005). Scientific realism. In Encyclopedia of philosophy. Gale Macmillan Reference USA.

Putnam, H. (1975). Mathematics, matter and method. Cambridge, Mass: Cambridge University Press.

Putnam, H. (1977). Realism and reason. In Proceedings and addresses of the American philosophical association (Vol. 50, No. 6, pp. 483-498). References are to the reprint in Putnam 1978a (pp. 123-140).

Putnam, H. (1978a). Meaning and the moral sciences. Boston: Routldge \& Kegan Paul.

Punam, H. (1978b). Reference and understanding. In Putnam (1978a, 97-119).

Putnam, H. (1978c). Equivalenza. In Enciclopedia Einaudi, Einaudi, Torino (Vol. V, pp. 547-564). English transl. Equivalence. In Putnam Realism and Reason, Philosophical papers vol. 3, Cambridge University Press, Cambreidge Mass (pp. 26-45).

Putnam, H. (1981). Reason, truth and history. Cambridge: Cambridge University Press.

Putnam, H. (1987). The many faces of realism. La Salle Ill: Open Court.

Putnam, H. (1994). Sense, nonsense and the senses: An inquiry into the powers of the human mind Dewey lectures at Columbia university. The Journal of Philosophy XCI n., 9, 445-517.

Putnam, H. (2012). Philosophy in an age of science. In: M. De Caro, D. Macarthur (Eds.), Harvard University Press, Cambridge, MA (Engl).

Sankey, H. (2008). Scientific realism and the rationality of science. Aldershot: Ashgate.

Schlick M. (1932a). Form and content, an introduction to philosophical thinking. In Gesammelte Aufsatze, 1926-1936 (pp. 151-249). Vienna: Gerold, 1938.

Schlick, M. (1932b). Positivismus und Realismus, Erkenntnis III, 1-31. English transl. Positivism and Realism. In Moritz Schlick, Philosophical Papers, vol. II (1925-1936) from Vienna Circle Collection, Dordrecht, Kluwer, 1979, 259-284. Repr. in The Philosophy of Science, ed. by R. Boyd, P. Gasper, J. D. Trout, MIT Press, Cambridge London (pp. 37-55).

Schlick, M. (1936). Meaning and verification. The Philosophical Review, 45(4), 339-369.

White, R. (2003). The epistemic advantage of prediction over accommodation. Mind, 112(448), $653-683$.

Wright, J. (2002). Some surprising phenomena and some unsatisfactory explanations of them. In S. Clarke \& T. D. Lyons (Eds.), Recent themes in thephilosophy of science. Scientific Realism and Commonsense (pp. 139-153). Dordrecht: Kluwer.

Publisher's note Springer Nature remains neutral with regard to jurisdictional claims in published maps and institutional affiliations.

Mario Alai (1952) graduated at the university of Bologna and holds graduate degrees from the universities of Urbino and Helsinki and two PhDs from the universities of Maryland and Florence. After teaching Religion, Psychology, History and Philosophy in high schools, he has worked at the University of Urbino as Researcher in Logics and Philosophy of Science, Associate professor of Theoretical Philosophy, and (currently) Associate professor of Philosophy of Language. His research concerns mainly the debates on scientific realism (especially deployment realism and the "no miracle" argument) and metaphysical realism (especially Carnap's, Putnam's and Goodman's antirealist views). He has also written on epistemology (knowledge, justification and skepticism), the theory of truth, artificial intelligence in scientific discovery, the history of philosophy of science, sense and reference, experimental philosophy, and the thought of Frege, Russell, Wittgenstein, Popper, Quine, D. Lewis and Agazzi. 